\title{
Serviço Social e o campo da saúde: para além de plantões e encaminhamentos
}

\section{Social Services and health policy: beyond shifts and forwarding}

\section{Francis Sodré}

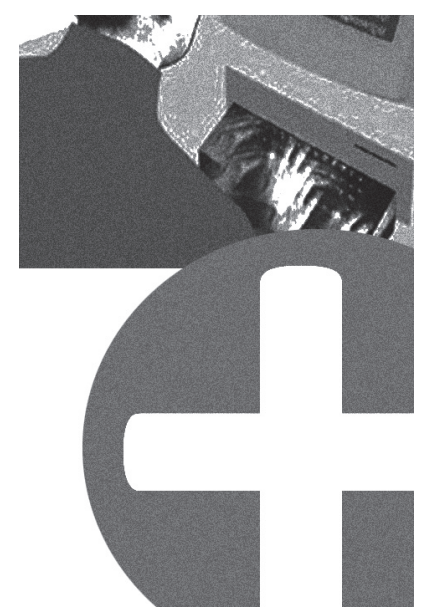

Resumo: Trata-se de um artigo que visa analisar a política de saúde e o trabalho do assistente social a partir de dois momentos distintos das formas de gestão do trabalho: o modelo fordista e o modelo de acumulação flexível. Esses dois eixos de análise serão discutidos aplicados ao campo da saúde e à inserção do trabalho do assistente social na saúde. Os dois eixos foram escolhidos para apontar um exame sobre tendências dos determinantes sociais à saúde pública e ao processo de trabalho do assistente social neste campo.

Palavras-chave: Serviço Social. Processo de Trabalho. Saúde Pública. Saúde Coletiva.

\begin{abstract}
This article aims at analyzing health policy and social work from two distinct forms of working management: Ford's model and the model of flexible accumulation. These two axes of analysis are discussed as applied to the field of health and to the integration of social work in health. The two axes were chosen to examine the trends of social determinants to health and the social worker's working process in this field.
\end{abstract}

Keywords: Social Services. Working process. Public health. Collective health.

* Assistente social e doutora em Saúde Coletiva, professora do Departamento de Serviço Social da Universidade Federal do Espírito Santo — Vitória/ES — Brasil. E-mail: francisodre@ uol.com.br. 


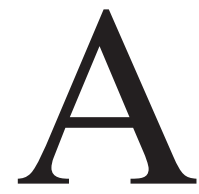

necessidade de escrever sobre o trabalho do assistente social no campo da saúde traz desafios recorrentes desde a inserção do profissional de Serviço Social nesta área de atuação. Temos há muito tempo acúmulo nas discussões produzidas para a saúde pública através das ferramentas que o Serviço Social, juntamente com outros profissionais, desenvolveu e aprimorou ao longo da reforma sanitária e da implantação do Sistema Único de Saúde (SUS), tornando-as coletivas.

Do conhecimento acumulado nas lutas sociais, o assistente social contribuiu para a politização do campo da saúde. Inseriu o debate sobre os determinantes sociais de forma definitiva e ainda hoje se insere nas frentes de trabalho para demarcar um posicionamento macropolítico que luta por um SUS menos biomédico nas suas mais diversas redes de serviços e especialidades.

Nas duas décadas de vida deste Sistema Único de Saúde comemoramos também trinta anos do Congresso da Virada, algo que não foi simples coincidência histórica. O nascimento do SUS é verdadeiramente um produto das lutas sociais, nas quais os assistentes sociais tiveram importante contribuição e trouxeram para si a afirmação de um referencial teórico até então hegemônico pautado nas reflexões de uma teoria social crítica e comprometida com um projeto de sociedade que determinou toda a história subsequente desta profissão.

$\mathrm{Na}$ área da saúde, verifica-se as interfaces da história e das políticas públicas que vivenciamos através das conexões estabelecidas com as políticas sobre a vida. O que é uma política de saúde se não uma política sobre a vida? Ou em chave marxista: as políticas de reprodução social. Neste campo das relações sociais, duas observações serão aqui pontuadas em diferentes momentos históricos dos processos de gestão do trabalho em saúde: o fordismo e a acumulação flexível em suas determinações na saúde — uma demarcação que fizemos para elucidar momentos diferenciados da política de saúde e que influenciam nas práticas dos profissionais, entre eles o assistente social inserido na saúde coletiva. Essa demarcação histórica norteará toda nossa análise no decorrer do debate que ora propomos. Esse exame sobre tendências está pautado na produção de Harvey (1989), que contrapõe dois momentos distintos nas formas de gestão do trabalho denominados por ele como fordismo e acumulação flexível. Desse arcabouço produzido pelo autor, aplicaremos tal análise ao campo da saúde, refletindo sobre a inserção dos assistentes sociais. 


\section{A Modernidade e o Fordismo na Saúde Pública}

A afirmação da industrialização por meio da formação de um amplo parque industrial abrigado em um discurso nacionalista trouxe a modernidade ao país. A industrialização endógena e financiada por um capital exógeno fez com que o Brasil vivenciasse um amplo processo de crescimento dos seus centros urbanos. Essa mesma industrialização trouxe consigo as mazelas de um trabalho de fábrica, conflitos urbanos e a criação de políticas de controle da força de trabalho.

Para o Serviço Social isso representou a necessidade de criação de práticas "modernas", a exigência de uma racionalidade burocrática-administrativa e a inserção do seu trabalho em estruturas institucionais complexas do ponto de vista organizacional. ${ }^{1} \mathrm{O}$ embate de tendências estruturalistas retomadas no Serviço Social e confrontadas com referenciais da psicologia e da sociologia caracterizam a chegada da modernidade à profissão.

No campo da saúde pública, foi o momento das grandes instituições centralizadas e verticalizadas em uma estrutura única de poder. A construção de um Estado forte e presente por meio do fomento às políticas sociais fez determinar a criação do campo da saúde pública. A própria terminologia "saúde pública" refere-se à formação de uma política estatal, portanto "pública" no seu sentido de ser atrelada ao Estado.

As instituições de porte estavam também correlacionadas à chegada dos grandes projetos industriais, principalmente aqueles que trouxeram a promessa do desenvolvimento ${ }^{2}$ econômico, invertendo o perfil populacional do Brasil rural para o Brasil urbano. Modelos americanizados de políticas públicas funcionalistas entravam em discussão, colocando o cerne do debate profissional do assistente social na clássica divisão caso/grupo/comunidade. Ou seja, o indivíduo, o grupo e a vida em sociedade eram tratados de forma estanque, como se fossem diferenciados ou como se não estivessem correlacionados.

1. Este raciocínio foi desenvolvido de forma muito qualificada no livro Ditadura e Serviço Social, de José Paulo Netto, com o requinte do detalhamento histórico que isso representou para o amadurecimento profissional do Serviço Social.

2. É interessante notar como a palavra "desenvolvimento" traz a noção de retirada do envolvimento (des-envolvimento), o que faz sentido à nossa história, que se pautou por uma modernização ditada por padrões internacionais. 
Esse misto entre funcionalismo e estruturalismo no campo do Serviço Social pautou práticas sociais importantes e momentos históricos para a profissão. Destaca-se entre eles a inserção maciça dos assistentes sociais nos grandes hospitais, o trabalho muitas vezes higienista de retirada das populações de rua com o discurso do sanitarismo organizado por meio de normas de higiene e cuidado com o corpo.

No Brasil, o Serviço Social demarcou sua entrada no campo da saúde pública pelo viés dos trabalhos com comunidade, por meio de práticas educativas sobre procedimentos de higiene aplicados à vida privada, incentivando o controle de natalidade, o controle de doenças infantis, de higiene bucal, de saneamento para a criação das primeiras políticas urbanas de saúde, muitas vezes realizado por meio de um trabalho educativo baseado em proporcionar acesso à informação sobre o próprio corpo e a higiene do mesmo. Esse era um trabalho que se mostrava necessário a um país sem escolaridade, com grande parte da população em condição de miséria e revelando desconhecimento sobre o próprio corpo.

Também nesse período, por meio das políticas urbanas, as abordagens individuais sobre a saúde foram desenvolvidas de forma ampla. O Serviço Social de caso para a saúde pública era a representação da necessidade de intervenção do assistente social nas políticas de reprodução social. Trazia ainda o reconhecimento de que a saúde possuía seus determinantes sociais, mas também a afirmação que muitos desses determinantes eram tratados isoladamente. Isso caracterizou uma ação maciça de atendimentos de "casos sociais" — quase um contrassenso.

Assim, o atendimento de caso nas grandes instituições se ampliou, apoiado em um excesso de demandas com o qual o assistente social teve de se deparar. A prática da sistematização se perdeu em muitas instituições devido ao grande contingente de pessoas atendidas.

Desse mesmo período, nasce nos hospitais públicos, como ferramenta do Serviço Social, o "livro preto". Um livro de ata, com capa preta, em que o assistente social relata o atendimento que chega até ele como registro de sua demanda. Atualmente, o "livro preto" está para o Serviço Social no campo da saúde como o Ford modelo T está para o fordismo - algo superado. Trata-se de um registro superficial, sem dados que venham a servir de fonte para uma sistematização qualificada. Registros pontuais realizados de acordo com a von- 
tade, o tempo e a decisão do assistente social no momento da chegada do usuário. Uma forma padronizada de dizer "resolva no próximo plantão". Assim, as demandas que chegam ao Serviço Social são tratadas como uma situação isolada fazendo com que o próprio assistente social desqualifique seu trabalho, não colocando a dimensão macrossocial que está contida em cada atendimento que realiza, ou melhor, não destacando a complexidade das manifestações da questão social naquela demanda trazida ao campo da saúde pública.

O grande hospital traz consigo a gestão do trabalho em um formato semelhante ao concebido dentro da grande fábrica. Atendimentos em massa, cirurgias em massa, internações contabilizadas pelo seu gasto financeiro, leitos em série e atendimentos sequenciais sem tempo de parada. Desta forma, aos poucos molda-se uma rotina também para aquele trabalho que não deveria ser considerado rotineiro. O Serviço Social criou e reproduziu normas institucionais de forma mecanizada para todos aqueles que o procuravam. Mas como não ter um texto pronto se a proposta institucional é seriada, dividida por especialidades? Em cada clínica, enfermaria ou ambulatório "apertam-se parafusos" em partes diferentes do corpo humano.

A especialidade técnica na saúde pública criou equipes que não interagem. São profissionais compartimentalizados, como se a vida fosse a junção de conhecimentos sobre pedaços do corpo humano. O "fordismo modernizador" proporcionou ao campo da saúde uma formação maciça de profissionais que tratam a vida como partes contidas em um todo. A estrutura administrativa centralizada do grande hospital, proporcionou a criação de um modelo de saúde-fábrica. Uma produção sem originalidade, centrada em um discurso de defesa do Estado protetor que nunca conhecemos através do fordismo na saúde pública.

A criação da saúde-fábrica deu origem também a formação dos primeiros cartéis de terceirização nos serviços de saúde. A criação dos planos de saúde ou mesmo a chegada decisiva de serviços especializados de grande custo que funcionam dentro dos hospitais públicos de todo o Brasil marcaram esse modelo. Em hospitais universitários, filantrópicos ou mesmo hospitais de médio porte, tornou-se comum o surgimento de serviços de hemodiálise, quimioterapia ou radioterapia, fornecidos por equipes que detêm o controle sobre as máquinas. Exatamente o mesmo formato capitalista do início da sociedade burguesa: um grupo de médicos detém as máquinas de radioterapia e por eles serem 
os donos das máquinas, fornecem (dentro de um serviço público) seus trabalhos altamente especializados, cobrando o quanto querem pelo serviço e sendo pagos pelo Estado. Este modelo de Estado-empresa ${ }^{3}$ reflete não só o campo da saúde, mas o único formato de Estado de bem-estar social que o país conheceu, reforçando teses dos estudos marxistas em que o Estado sempre foi a representação de uma classe.

Para o Serviço Social, isso não foi muito diferente. A hegemonia do discurso biomédico dentro da instituição hospitalar reforçou uma atitude aguerrida dos assistentes sociais para afirmarem seu espaço na saúde pública. O modelo estatal era pautado pela atuação no grande hospital-fábrica ou nos centros de saúde que funcionavam por meio de um modelo militar campanhista. A associação entre ambos formava uma lógica dual de atuação exclusiva para o campo da saúde. A inserção dos assistentes sociais nesses dois âmbitos proporcionava questionamentos de politização da saúde que não só se resumiam a esse modelo dual, mas a outras formas de inserção e outras formações de um discurso não hegemônico à saúde pública. Este questionamento já demarcava os idos dos anos 1980 com a inserção decisiva da teoria social crítica no debate profissional. Também a crítica ao Estado classista que convivia, contraditoriamente, com referenciais fenomenológicos e outras correntes de pensamento que à época formavam os debates da sociologia e da filosofia.

Não se pode afirmar que todo esse contexto histórico tenha gerado uma atuação específica dos assistentes sociais no campo da saúde, mas surgem nesse momento histórico, em reposta à saúde-fábrica, o modelo de resistência também pautado na ideologia de uma produção em massa e em série: associações de assistentes sociais da oncologia, da infância, da clínica... como se a profissão estivesse de fato inserida na serialização da saúde pública que o Estado fordista criou.

Em outro ponto de vista, o livro de Maria Inês de Souza Bravo, que narra a trajetória do Serviço Social na reforma sanitária, ${ }^{4}$ mostra também outras formas de resistência, lutas coletivas, em que os assistentes sociais foram aliados dos movimentos de moradia, de luta pela saúde e pela políticas urbanas de saneamento básico - um reflexo que apontava para transições ou deslocamentos do modelo vigente trazendo os ideais do sanitarismo.

\footnotetext{
3. A terminologia Estado-empresa foi retirada do livro Trabalho e cidadania de Giuseppe Cocco.

4. Estamos nos referindo ao livro Serviço Social e Reforma Sanitária, publicado pela Cortez Editora.
} 
Por isso à saúde-fábrica atribui-se a lógica intervencionista estatal como se as políticas de saúde criadas pelo Estado não fossem passíveis de ser questionadas, pois trazem consigo uma falsa noção que exercem unicamente o "bem comum". As políticas fordistas ao campo da saúde proporcionaram uma contraditoriedade: por um lado, um avanço no campo das conquistas pelas lutas sociais em criar, executar e garantir as políticas sociais de saúde; por outro, no campo do Serviço Social, criou "legitimidade" de um discurso "estatalista" que reforçava as políticas fordistas intervencionistas como algo legítimo, provedor de bem-estar para a sociedade. $\mathrm{O}$ discurso do Estado provedor esteve presente em muitos meios acadêmicos, como se o Estado não fosse porta-voz dos interesses de classe. Com certa opacidade, isso legitimou a entrada violenta do capital privado nos serviços públicos e a lógica privatista e privatizante de muitas dessas políticas.

Por essas ações do jogo macropolítico, o Estado fordista pode ser considerado o Estado-empresa, pois colocou dentro das instituições públicas o modo de produção gerido "em parceria" entre o público e o privado, como se isso fosse o caminho "natural" das coisas. Esse cenário, introduzido de forma ampliada pelo discurso modernizador industrial no campo da saúde, abriu os precedentes necessários para a chegada do neoliberalismo na década seguinte.

A saúde pública sofreu refrações desse discurso. A construção das grandes instituições de saúde verticalizadas e associadas à Previdência Social no controle da força de trabalho foi aliada ao fordismo estatal. A política "modernizadora" de industrialização só foi possível no cenário brasileiro quando associada à Previdência (que funcionava como uma seguradora privada) e à Saúde (que cuidava de vidas como se cuidasse somente de corpos aptos ao trabalho).

No campo das práticas, foi sob a égide desse modelo que foi criado o prontuário do usuário separado por atuação profissional. $\mathrm{O}$ assistente social tinha o seu prontuário, e os demais profissionais tinham outros. Por onde o usuário da saúde passava deixava um registro em uma "gaveta" diferente. O argumento para isso foi a ética do sigilo profissional. ${ }^{5}$ Algo que não diz nada

5. "Os assistentes sociais dispõem de um manancial de denúncias sobre a violação de direitos humanos e sociais e, desde que não firam as prescrições éticas do sigilo profissional podem ser difundidas e repassadas aos órgãos de representação e meios de comunicação atribuindo-lhes visibilidade pública na defesa dos direitos [...] Por meio da socialização de informações procura-se tornar transparente, aos sujeitos que busca os serviços, as reais implicações de suas demandas — para além das aparências e dos dados imediatos assim como os meios e condições de ter acesso aos direitos. Nesse sentido, essa abordagem extrapola uma 
ao usuário que segue de porta em porta de uma mesma instituição e não recebe um retorno dos profissionais que não dialogam entre si. Sabemos que as informações sigilosas podem ser sistematizadas em um documento à parte que fique sob a guarda do assistente social, por isso não explicam a compartimentalização das informações. Não temos claro até que ponto tal atitude seja, em vez da "ética do sigilo", a "ética do corporativismo". O prontuário não pode servir de instrumento de diálogo se cada um só quer dialogar apenas com seus pares. Neste jogo, somente o usuário perde, pois não encontra equipes provocativas que coloquem no centro das discussões um debate sobre a demanda atendida. Desta forma, reproduz-se serviços hierarquizados, padronizados, centralizados, compartimentalizados e corporativistas, como o fordismo nos ensinou.

Os assistentes sociais precisam atentar para não repetir o modelo de produção em massa, que no caso da saúde-fábrica pode ser compreendido por plantões e encaminhamentos. Aquele arquétipo resumido em uma sala, um livro preto, um assistente social e uma agenda antiga com contatos telefônicos desatualizados. O que poderia ser equiparado ao médico que só entrega receitas. Este modelo não condiz com o discurso que foi criado pelo Serviço Social, que apregoa a emancipação humana como princípio. O que a instância hospitalar proporcionou à formação profissional foi uma lógica inserida na dimensão histórica maior da instituição - uma máquina de fabricar produtos sem sentidos para o seu produtor e para o seu demandante. Produtos que se esgotam em si mesmos e perdem a dimensão processual do trabalho do assistente social.

O modelo saúde-fábrica cria as bases para a atuação pautada em um discurso moralizador, que trata a pobreza como algo irreversível ou as instituições como um âmbito da política pública em que não há caminhos para mudanças. De forma ampliada, introjeta no campo da saúde pública a naturalização da pobreza, despolitiza a miséria, realizando serviços pobres e práticas esvaziadas aos mais pobres. Gera um vazio de sentidos às instituições, aos profissionais e aos usuários, em um conformismo que reforça a banalização da pobreza em todos os âmbitos da vida.

\footnotetext{
abordagem com um foco exclusivamente individual, ainda que, por vezes, realizada a um único indivíduo - a medida que considera a realidade dos sujeitos como parte de uma coletividade. Impulsiona, assim, também a integração de recursos sociais que forneça retaguarda aos encaminhamentos sociais e a articulação do trabalho com as forças organizadas da sociedade civil, abrindo canais para a articulação do indivíduo com grupos e/ou entidades representativas, capazes de negociar interesses comuns na esfera pública" (Iamamoto, p. 428, 2007).
} 


\section{A Saúde, o Serviço Social e o Modelo de Acumulação Flexível}

Os anos 1990 inseriram de forma ampliada a transição do fordismo-taylorismo para as modos flexíveis de acumulação (o toytismo foi o maior exemplo). Proporcionou o envio das fábricas para regiões sem tradição industrial, com maiores perspectivas de exploração da classe trabalhadora — o que veio a incrementar novas formas de extração de superlucros. Todo esse contexto favorece a "naturalização" da mercantilização da vida no capitalismo avançado, transformando os cidadão sujeito de direito em um "cidadão consumidor", ${ }^{6}$ o desempregado em um "empreededor" ou em mero cliente das políticas de assistência social focalizadas. Este mesmo cenário, aprofundado em períodos neoliberais, demarcou o crescimento de inciativas da sociedade civil, por meio da expansão das ONGs, do voluntariado, da filantropia e do denominado "terceiro setor".

Nesse quadro de profundas perdas para os trabalhadores, foi se desfazendo o seu potencial político-organizativo. Entre outros fatores, as novas práticas flexíveis de gestão da força de trabalho, o trabalho por domicílio, o trabalho nas infovias de comunicação, as terceirizações, o trabalho parcial, temporário e fragmentado estabeleceram mecanismos e novos meios de controle e dominação sobre a classe trabalhadora com o argumento falso e perverso da "empregabilidade".

É interessante notar como essas mudanças nos modelos de gestão da força de trabalho desencadeiam influências importantes sobre o campo da saúde. Na evolução do discurso dos campos de conhecimento, percebe-se um deslocamento entre as terminologias saúde pública e saúde coletiva. Pode-se, de forma breve, introduzir que o campo da saúde coletiva traz questionamentos às políticas públicas de saúde em seu formato gerido unicamente pelo Estado "parceiro" das empresas de saúde. Cabe aqui destacar exemplos como a indústria de equipamentos hospitalares, os cartéis dos planos de saúde, a indústria de medicamentos e as organizações não governamentais, ${ }^{7}$ tão presentes na atual política de saúde.

6. Ana Elisabete Mota desenvolveu tais conceitos em dois momentos diferenciados de suas obras, destacamos aqui o livro Cultura da crise e Seguridade Social e, atualmente, O mito da assistência social, ambos publicados pela Cortez Editora.

7. Atualmente tornou-se impossível pensar a política de saúde sem a participação das ONGs. Exemplo disso são as casas de recuperação de dependentes químicos (muitas delas com vertentes religiosas), as co- 
A nomenclatura "saúde coletiva" não representa apenas uma mudança entre termos, mas a incorporação de questionamentos trazidos principalmente pelas lutas sociais. A saúde coletiva desperta para o fato de que o motor do desenvolvimento das políticas públicas são os movimentos de resistência, e não a modernização proposta por mais industrialização. Para a saúde, um campo empírico por excelência, o acúmulo já produzido pela reforma sanitária forneceu elementos suficientes para este entendimento. Despertou-nos para o fato de que não será mais industrialização que trará desenvolvimento, mas sim a abertura definitiva de um diálogo do Estado com as lutas sociais — admitindo a demanda dos movimentos como agenda das políticas públicas.

Tomando esse raciocínio como central a esse segundo momento de análise, podemos inferir que do ponto de vista dos movimentos de resistência, a década de 1990 foi a expressão máxima de que esse jogo estava temporariamente perdido. A chegada avassaladora do neoliberalismo às políticas de saúde deixou muito claro, por um lado, os atores sociais que disputavam projetos privatistas de saúde e, por outro lado, a continuidade dos ideais da reforma sanitária. ${ }^{8}$ Esse embate que marcou a década passada deixou-nos heranças muito representativas, a maior delas o silenciamento dos movimentos.

As lutas sociais do trabalho na década de 1990 expressaram a fragmentação da classe trabalhadora em diversas formas de vínculos e contratos empregatícios que manifestaram a precarização das relações de trabalho no período de crise do fordismo. Por muitos, esse período foi denominado como sendo de acumulação flexível, guiando várias formas de gerir não somente o campo das políticas do trabalho, mas também, nesse caso, as formas de gestão das políticas de saúde.

Diante desse quadro, o assistente social demarcou de forma vertical sua atuação na reprodução das relações sociais. Na saúde coletiva, foi o reflexo dos questionamentos que tentavam distanciar o fordismo das políticas de saúde, um questionamento definitivo ao modelo saúde-fábrica. Criou-se como principal estratégia para operacionalizar seu posicionamento no campo um modelo denominado estratégia de saúde da família (ESF). Diferentemente da lógica de

\footnotetext{
munidades terapêuticas, as casas de acolhida de pessoas portadoras do vírus HIV/Aids, voluntários de organizações que recebem vítimas de violência, entre muitas outras.

8. Maria Inês Bravo formula uma importante discussão sobre o tema no livro Política social e democracia, publicado pela Cortez Editora e pela UERJ em 2001.
} 
produção fordista, a produção passava a ser por demanda, e não em série. O trabalho dos profissionais da saúde retomava uma antiga discussão no campo das ciências: o retorno do generalista e a crítica ao especialista.

A ESF retomou o debate que propunha menos operários que apertassem somente parafusos, mas inseria uma leitura de que as políticas de saúde são de fato políticas sobre a vida, por isso não são objeto de forma exclusiva a um único saber profissional ou peça a ser trocada por um especialista. O discurso científico pedia a ampliação do campo, alargava as bases de análise e a tornava multiprofissional de forma definitiva. Com isso, passa a existir um chamamento ao discurso da participação e da multiplicidade.

Outro momento importante foi a criação das equipes de agentes comunitários. Os agentes precisavam ser locais, "nativos" em seus territórios de trabalho. Os agentes de saúde saem todos os dias das unidades de saúde com o objetivo de capturar os "nichos", exatamente como no modelo de acumulação flexível. Em cada casa que se entra busca-se o hábito, o comum, o cotidiano, o corriqueiro, a rotina para se compreender a "saúde como estilo", como forma de vida.

Criou-se novos indicadores para compreender as políticas de saúde. Isso não foi uma peculiaridade brasileira, mas internacional. O fato é que "qualidade de vida" (um critério extremamente subjetivo) tornou-se mensurável. "Qualidade" e "estilo" compõem atualmente um mesmo critério de análise, um critério que passou a ser medido e capturado como estilo de vida saudável.

Isso proporciona aos assistentes sociais, profissionais da saúde, dois pontos de reflexão: 1) Frente aos determinantes sociais que conhecemos sobre a saúde, o que seria um estilo de vida saudável? Iremos pontuar a miséria e a pobreza como critério de avaliação ou encontraremos estilos saudáveis mesmo dentro das condições de pobreza da população?; 2) O que essa inversão proposta pelo campo da saúde coletiva nos coloca como demanda? Que modos de reprodução da vida estão sendo pautados?

No início dos anos 2000 assistiu-se à contratação em grande escala de agentes comunitários. Durante um longo período tomou-se conhecimento de que o trabalho do agente comunitário era basicamente centrado no ato de entrar de casa em casa, obter delas informações importantes para direcionar o trabalho das equipes de saúde da família nas unidades. Este trabalho, se feito de forma mais politizada, traria uma processualidade interessante à saúde — uma provável 
perspectiva de continuidade com diálogos mais profícuos com a população. Os assistentes sociais perceberam com isso a perda de um espaço no mercado.

A técnica de vista domiciliar é parte da história da profissão do assistente social. Entramos no âmbito privado da vida das pessoas, no espaço residencial, doméstico. Certamente, para usar a linguagem biomédica, um procedimento invasivo. A visita domiciliar proporciona essa leitura sobre o privado, uma busca por informações que personalizam a ação do profissional com seu usuário; portanto, uma ferramenta perfeita ao modelo flexível de saúde.

Para a saúde coletiva, o território tornou-se o foco da ação; milimetricamente esquadrinhado, os hábitos e as manifestações da cultura local são colocados como determinantes sociais da saúde. Aliás, nunca os determinantes sociais foram tão evidentes à saúde, operando de forma clara, marcando a esfera da reprodução social. As dinâmicas dos territórios são dinâmicas locais com influências das políticas mundializantes, a cultura se manifesta nesse diverso, e os hábitos tornam-se a fonte primária para trabalhar a saúde como produto final da ação profissional.

O que aqui queremos afirmar é que esse trabalho requer uma ação política por excelência. Dinamizar redes, ativar e conhecer as dinâmicas produtivas dos territórios, conhecer hábitos e a cotidianeidade da coletividade posta em análise nas lentes das unidades de saúde focadas no território. Um trabalho característico da ação de um profissional de Serviço Social. ${ }^{9}$

Nos hospitais, a saúde coletiva também proporcionou um olhar flexível sobre a relação saúde-doença. Aqui queremos chamar a atenção para um discurso que circula com fluidez entre os profissionais da saúde e entre os assistentes sociais que atuam no campo da gestão: o discurso da humanização. Pontuamos a humanização como discurso porque ela é parte de uma série de

9. A categoria profissional ainda não conseguiu garantir que o número de assistentes sociais seja ampliado nas unidades de saúde para fazer a proposta de qualificar a intervenção dos trabalhos com as famílias e as redes sociais dos territórios do SUS. Ainda vigora, na maior parte das unidades de saúde do Brasil, que somente um assistente social dê conta de todo o trabalho com a população local, mensurado nos mapas dos gestores que tentam ser cartesianos na saúde pública, salvo raras exceções. Não é preciso rever as formas de intervenção do nosso trabalho social com os moradores das mais diversas regiões, mas sim rever os critérios do SUS, que se baseiam em quantitativos de habitantes que só se tonariam possíveis de ser trabalhados de forma fordista, em massa. Não é esta a intenção de um trabalho qualificado nos territórios para alcançar a política de saúde que almejamos. O SUS que queremos está longe das condições de trabalho postas aos profissionais de saúde. 
ações que dizem tornar humano aquilo que não possui formas ou atitudes humanas. Retirar a centralidade do trabalho morto, aquilo que está incorporado às máquinas, e recolocar a centralidade do trabalho vivo na saúde — objetivar-se na ação humana.

Tem-se por pré-sabido que o discurso da humanização propõe as mesmas ações planejadas pelas formas formas flexíveis de acumulação: atenção, acolhimento, cuidado, criar vínculos — afetividade posta em um processo de trabalho que se dá em ato. Esse processo de trabalho humanizador, ao mesmo tempo que proporciona relações mais abertas com o usuário, também abre precedentes para trabalhos mais alienantes do ponto de vista da sua execução. Certa vez ouvi de um profissional da saúde: "É fácil ser 'humanizador' com alguém que está vulnerável”. E tomamos então isto como ponto principal de nossa análise, nos direcionando aos assistentes sociais gestores das políticas públicas.

Há uma ambiguidade no discurso da humanização. Se por um lado promove menos máquinas, menos produção em série, menos fordismo na saúde, por outro traz uma prática extremamente alienante, tanto do ponto de vista do profissional da saúde, quanto para seu usuário. No campo hospitalar, hoje, os usuários caracterizam-se por pessoas doentes. Não existem pessoas saudáveis em busca de atendimento hospitalar. Neste sentido, qualquer um desses demandantes estão ali à espera de qualquer profissional que lhe dê o mínimo de atenção, de escuta ou mesmo uma ínfima informação. Assim compreende-se melhor a frase acima citada, ouvida de um profissional de saúde. Em situação extremamente vulnerável, qualquer discurso profissional que contenha mínimas informações pode ser entendido como "humano" ao usuário.

Por outro lado, do ponto de vista do trabalhador, o modelo flexível da saúde propõe um profissional de saúde participativo, que introjete certa docilidade, seja compreensivo na ação, sensível em seus procedimentos ou palavras. O gestor humanizante é aquele que transmite informações, tenta não tratar de forma piramidal seus modos de gerir e que ainda atenda o usuário para se tornar próximo a ele. Um modelo de trabalhador pressuposto pela acumulação flexível ${ }^{10}$

10. Não se pode perder de vista que o modelo de acumulação flexível ditou uma "flexibilidade" nas relações de trabalho, mas também nos processos, nas formas de produção, nas relações de consumo, e uma desregulamentação dos direitos do trabalho. 
como participativo; aquele que além do trabalho feito com as mãos, tão caro ao âmbito hospitalar, é também requerido em seu espírito - sempre compreensivo e atento ao outro, independentemente de suas condições de trabalho. Ou seja, uma evidência que os níveis de exploração sobre o trabalhador da saúde atual chegaram ao extremo em suas formas de exploração.

O assistente social tem sido cada vez mais convocado a atuar na gestão dessa força de trabalho no campo da saúde, algo que nos desafia a pensar sobre essas relações de forma mais aprofundada. Ao profissional que se resume a dar plantões e encaminhamentos, as políticas de saúde lhe reservam lugares extenuantes de trabalho, equipes despreparadas, ambientes insalubres, condições inferiores de administrar seu processo de trabalho no atendimento aos usuários. O modelo flexivel da saúde requer um assistente social para além do arquétipo "plantão-encaminhamento". Um caminho de mão dupla que abre janelas para longos debates.

Não existe aqui intencionalidade de dizer que o plantão do Serviço Social é uma atividade desnecessária ou superada, pois sabemos bem que ele se constitui, muitas vezes, como a única porta de entrada realmente existente aos usuários das instituições tradicionais; um momento em que o usuário é recebido para ser ouvido em sua queixa sobre a própria instituição, buscar orientações breves, complementar um atendimento realizado por outro profissional (e que o usuário sai de lá sem as informações que realmente necessitava), abrir um diálogo com os canais da rede de serviços ou mesmo intrainstitucionais. No entanto, atentamos para o fato de que o trabalho desse assistente social não pode se esgotar nisso, como se encontrasse um fim em si mesmo.

O assistente social despreparado continua a repetir que "apaga incêndios" ou que somente resolve problemas nos hospitais. Mas quem não resolve problemas em hospitais? A instituição hospitalar colocou-se na modernidade como uma máquina de resolver problemas de saúde. Todos no campo hospitalar atuam com a finalidade de desenvolver estratégias para fazer viver, ampliar a sobrevida, retirar a população que lhe demanda de uma condição de sofrimento, que na maior parte das vezes trata-se de um sofrimento físico ou psicológico.

A maneira como se deu (e ainda acontece) a implantação da política de saúde traz aspectos importantes para analisar a forma fabril de fazer a ação de Estado. O assistente social é solicitado, durante todo o seu tempo de trabalho, a atender demandas complexas, de forma desmedida pode ser considerada a sua 
intensidade. Por vezes, o atendimento a uma só pessoa pode ocupar dias de trabalho devido a sua complexidade. E mesmo com demandas grandes e intensas de atendimento direto à população, é também convocado a ocupar cargos que dialogam com a gestão.

$\mathrm{O}$ projeto de lei ${ }^{11}$ que defende trinta horas semanais de trabalho para o assistente social tem no seu excesso, intensidade e sobrecarga de trabalho a base de toda a discussão apresentada em 2008. A questão trabalhista maior centra-se na forma em como fazer reconhecer nesse perfil de trabalhador sua peculiaridade de ação profissional sem destituí-la em seu salário. Um claro dilema fabril do trabalho mensurado através da hora trabalhada ou do produto concreto que produz, e não pela sua processualidade, como se dá entre todas as demais profissões que atuam na reprodução da vida.

\section{Informação é capital}

Diante desse cenário, temos assistido de forma ainda muito tímida o crescimento da demanda por pesquisa ou assessoria para as políticas públicas de saúde. As pesquisas solicitadas aos assistentes sociais pedem que os mesmos realizem uma interface entre os dados empíricos obtidos com a política executada, geralmente por órgãos públicos. É interessante notar como a produção do assistente social nesta leitura macropolítica sobre a realidade da saúde agrega capital ao Estado na sua forma de direcionar os serviços e os programas de governo.

A produção de informação sistematizada e qualificada pelo assistente social proporciona leituras que subsidiam o trabalho do gestor. No modelo de acumulação flexível, a informação tornou-se um capital valiosíssimo. Daí o crescimento da demanda por pesquisas e estudos que precedem as ações dos gestores das políticas sociais. A dimensão investigativa do trabalho do assistente social tem sido também demandada por outros fatores, não dependendo exclusivamente de uma "atitude" desse profissional.

11. Em 2008 foi extenso o debate sobre o projeto de lei que pleiteava trinta horas semanais de trabalho para o assistente social. A jornada reduzida visa primordialmente preservar a saúde e a segurança do profissional. 
A produção de pesquisa tem sido demandada de forma mais constante ao assistente social, que hoje tem se preocupado com a sua inserção nas pós-graduações tanto lato sensu quanto stricto sensu. Essa preocupação aparece de forma recorrente entre aqueles assistentes sociais interessados em atualizar conhecimentos e produzir uma prática crítica. Mesmo nas cidades que fogem ao circuito das grandes metrópoles, essa necessidade em qualificar-se e inserir estudos à sua prática começa a tomar maiores proporções. Sabemos que a inserção nos cursos de especialização ou mestrados não garantem a continuidade da prática da pesquisa em seus ambientes de trabalho, todavia desperta o interesse e o experimento nesse campo, atentando para a necessidade e a realidade que esse trabalho não seja necessariamente exclusivo dos meios acadêmicos.

$\mathrm{O}$ atual momento do Serviço Social deixa claro sua intencionalidade de buscar incessantemente o novo. Uma busca pelas tendências às demandas dos usuários que traz a sua inserção definitiva na prática da pesquisa dentro das instituições públicas e privadas. O Sistema Único de Assistência Social, modelo criado a partir da experiência do SUS, já mostra a preocupação com a criação do cargo de pesquisador como parte do âmbito da gestão. ${ }^{12}$ Informação sistematizada e geração de conhecimento associado à produção tornam-se um capital importante às novas formas de gestão. "O conhecimento não é só um verniz que se sobrepõe superficialmente à prática profissional, podendo ser dispensado, mas é um meio pelo qual é possível decifrar a realidade e clarear a condução do trabalho a ser realizado", diz Iamamoto (2001, p. 63).

No modelo "flexível" de produção da saúde a pesquisa não tem sido uma alternativa ou mera liberalidade do profissional em escolher com ela trabalhar ou não. Por mais que ainda apresente um caráter de sazonalidade nas formas como são produzidas, geralmente atendendo a interesses imediatos dos profissionais, verifica-se um novo momento em que o assistente social é convocado a produzir sistematizações mais elaboradas, traduzindo-se em processos de análise que requerem maior disponibilidade de tempo para a percepção de novas demandas ou a identificação de tendências e possibilidades na ação das políticas públicas e sociais.

Essa forma de planejar seu trabalho, uma forma que contém e pressupõe a pesquisa, não se esgota somente na coleta de depoimentos de usuários ou

12. Ainda é necessário superar essa herança binária na gestão das políticas sociais em que o "pesquisador" realiza o trabalho do pensar e os demais situam-se na "execução". 
gestores. Resulta em saber ler as produções estatísticas excessivamente produzidas por bancos de dados infinitos na atualidade, fazer o cruzamento das informações, produzir certa análise de conjuntura à luz desses dados e dar respostas criativas e embasadas em pressupostos teóricos sobre seu trabalho. Esgota-se o entendimento de que a pesquisa nas instituições começa e termina em uma simples fase coleta de dados em campo. Sua dimensão investigativa de maneira contínua é o que insere o diferencial da ação, recombinando vários instrumentos, fases, referenciais, sistematizações e reflexões críticas sobre os dados levantados.

É exatamente nessa dimensão investigativa do trabalho que imprimimos uma noção constituinte do direito à saúde e aos serviços sociais. Quando os assistentes sociais pensam a realidade, capturando o seu movimento, projetam e imprimem ações que proporcionam enxergar a necessidade de ampliação e de universalização. Assim, em vez de compreender o direito como um campo que se esgota na lei, no constituído, passam a visualizá-lo como um campo aberto, em que novas demandas se reconfiguram, fazendo imprimir a necessidade de pensar as leis, o acesso, a política e a universalização de forma cada vez mais ampla.

Por outro lado, também as próprias instituições públicas começam a criar suas estratégias para garantir seus pactos corporativos diante de tal crescimento da publicação de estudos e pesquisas sobre órgãos públicos. Se antes os comitês de ética e pesquisa eram uma prerrogativa do trabalho acadêmico hoje, as instituições públicas tentam se resguardar criando seus próprios comitês de ética, os quais burocratizam por meses a entrada de determinados estudos em campo para coleta de dados. Uma forma clara de dizer não à cientificidade quando atinge as bases críticas das políticas públicas.

Os comitês de ética criam verdadeiras barreiras burocráticas a estudos que não venham de suas próprias demandas. As Secretarias Estaduais de Saúde, municipais, hospitais públicos e unidades de saúde colocam profissionais desautorizados a falar em nome dos serviços que atuam, se antes não passar pelo aval dos seus comitês internos. Os assistentes sociais, que sempre estiveram na porta de entrada das instituições públicas de saúde, são hoje muitos dos que estão entre aqueles que não permitem a entrada de pesquisadores nas instituições de saúde pública sem ter antes uma carta de apresentação dos seus próprios comitês internos. 
Mas não são instituições públicas? Por que assistentes sociais não fornecem depoimentos a pesquisas acadêmicas sem ordem dos seus gestores? Será uma nova ditadura provocada pela burocracia estatal contra a transparência da informação? Não está, pois, em nosso código de ética, o nosso papel na construção do conhecimento científico? As instituições públicas têm criado, no campo da saúde, ao invés de comitês de ética, a ética dos comitês, autorizando a entrada de pesquisadores que não representam ameças aos seus gestores e, também, assistentes sociais que não fazem uso de sua liberdade ou autonomia para falar sobre seu próprio trabalho ou o de suas equipes.

O trabalho com a pesquisa sempre foi uma realidade das instituições de saúde, principalmente os hospitais. No entanto, na atualidade isto vem se estendendo para as unidades de saúde e ampliando-se para secretarias, fazendo crescer a figura do gestor com a função específica de produzir estudos e pesquisas no campo da saúde. Muitas vezes, esse gestor no campo das políticas públicas voltadas para a saúde tem sido um assistente social. Temos por certo a preocupação com o campo da pesquisa associada à gestão; entretanto, o que se mostra novo é que muitos assistentes sociais organizam comitês de pesquisa nas instituições e dificultam a entrada de pesquisadores que sejam externos à gestão das políticas públicas e sociais.

\section{0 processo de trabalho do assistente social e as novas demandas para a saúde}

Não é recente o conflito em que o assistente social se insere e que demarca os interesses polarizados entre as instituições sociais e as necessidades dos usuários na busca pelo acesso aos serviços sociais. Esse espaço tensionado torna-se inevitável às profissões que atuam nas políticas sociais durante os séculos XIX e XX, por meio do reconhecimento dos direitos sociais. O caráter social do Estado, sob a forma de direitos de cidadania, reconhece formalmente a exploração, a impossibilidade de satisfação das necessidades básicas da vida tendo como única fonte o salário direto.

O que se traz como elemento de análise é o processo de trabalho do assistente social que tem seu objeto manifesto nas expressões das contradições da questão social. Por isso, o Serviço Social não está vinculado às profissões que geram produtos materiais, concretos. Ele atua nas condições de vida, reprodu- 
zindo aquelas condições que são indispensáveis ao funcionamento de uma ordem - o que, no campo da saúde, ganha evidências expressivas.

Temos como pressuposto que toda riqueza existente é fruto do trabalho humano. Essa riqueza é redistribuída na forma de rendimentos distintos, bem como parte dela é transferida ao Estado, especialmente sob a forma de impostos e taxas pagas pela população. Por outro lado, parte dessa riqueza apropriada é transferida para a classe trabalhadora sob a forma de serviços sociais. Desta maneira, muitas vezes tais serviços ganham a forma de "doação" ou "benefício". Em nosso caso, as políticas de saúde se travestem claramente com esse perfil "provedor" de Estado, aparecendo como políticas sobre a vida, com forte nuance "humanizadora".

Merece destaque o processo de trabalho do assistente social em sua dimensão educativa dentro dessa política aparentemente provedora de um "bem comum". $\mathrm{O}$ assistente social realiza atividades que incidem sobre comportamentos e atitudes da população e tem na linguagem seu principal instrumento privilegiado de ação. Isso lhe permite trabalhar nas expressões concretas das relações sociais, no cotidiano da vida dos sujeitos e faz com que disponha de relativa autonomia na condução do exercício de suas funções institucionais (Iamamoto, 2007).

Nas ações de execução das políticas de saúde, esse perfil "humanizador" da política social ganha maior visibilidade, visto que o o trabalho dos profissionais da saúde, neste caso do assistente social, cria os nexos de ligação entre os interesses de Estado e os dos usuários por meio da linguagem, uma ação eminentemente humana. Por intermédio dessa dimensão do trabalho vivo, pode-se afirmar que nunca seu processo de trabalho será idêntico, ainda que as tentativas dos interesses de seu empregador sejam transformar esse trabalho em uma ação serializada, maciça, sem reflexão contida na ação.

O assistente social é proprietário de sua força de trabalho especializada. Ela é produto da formação universitária que o capacita a realizar um "trabalho complexo", nos termos de Marx. Essa mercadoria, força de trabalho, é uma potência, que só se transforma em atividade - em trabalho, quando aliada aos meios necessários à sua realização, grande parte dos quais se encontra monopolizado pelos empregadores: recursos financeiros, materiais e humanos necessários à realização deste trabalho concreto, que supõe programas, projetos e atendimentos diretos previstos pelas políticas institucionais (Iamamoto, 2007, p. 421).

Nesse processo histórico, Iamamoto (2007) acrescenta que o trabalho do Serviço Social possui a chancela da "sanção social e institucional", produzindo 
efeitos diversos como porta-voz das políticas públicas, atestando uma possível "polivalência" ou intervenção profissionalizada dentro dos aparelhos de Estado (p. 275). Será esse o efeito mimético do processo de trabalho do assistente social dentro da execução das políticas sociais. Um efeito que provoca e se autorrefere à sua execução como uma intervenção compensatória, imediata e aparentemente benevolente.

Toda política social é apenas um fragmento das políticas públicas. Não se tem o esgotamento das questão social por meio da ação dos profissionais que atuam e executam as políticas sociais, mesmo porque não é interesse da ordem econômica e social vigente que isso de fato se concretize. As instituições empregadoras dos assistentes sociais dependem de uma prévia fragmentação das políticas definidas pelos organismos empregadores que estabelecem as prioridades das políticas públicas como um todo. Atuar na questão social por meio das políticas sociais representa apenas uma parte da ação de um todo que o compromisso profissional do Serviço Social quer extinguir: as múltiplas expressões da questão social.

Na saúde isso não é diferente. Assim como em todas as outras políticas sociais, a saúde tem vivenciado algumas tendências no seu diálogo com o Estado para a formação de novas agendas para a política pública. Os movimentos sociais atuais, congregados, por exemplo, no Fórum Social Mundial da Saúde, demostram que as novas lutas trazem muito mais que reivindicações por leitos em hospitais ou "humanização" da atenção. As agendas formadas dentro desses movimentos apontam para um debate que começa a pautar um novo modelo de seguridade social ampliado, mundial. $\mathrm{Ou}$, em outros aspectos, trazem como debate a quebra de patentes de medicamentos monopolizados nas mãos de laboratórios internacionais - verdadeiras manifestações de um capital mundializado. Pautam ainda o direito de exercer a profissão de qualquer profissional da saúde, independentemente de sua nacionalidade, em qualquer país. $O$ fórum de trabalhadores da saúde do Mercosul trouxe-nos essa demanda. ${ }^{13}$

13. O Mercosul Salud é formado por profissionais de saúde, entidades e representações dos movimentos sociais da América do Sul em prol do livre exercício de suas profissões em qualquer país do Cone Sul. Os profissionais de saúde que o compõem pleiteiam o direito de ser enfermeiros, médicos, nutricionistas, psicólogos, fisioterapeutas etc., em qualquer país do bloco, sem barreiras nacionais por motivos da localidade de sua formação. Os assistentes sociais são representados por uma comissão de profissionais ligados ao CFESS nesta rede. Os debates acontecem a cada seis meses com todos os ministros da Saúde do Mercosul e as referidas representações, além da Organização Pan-Americana de Saúde (Opas) e a Organização Mundial de 
Em épocas de "capital fetiche", o que temos por pressuposto ao estudar o processo de trabalho do assistente social no campo da saúde é que não existe um processo de trabalho do Serviço Social, visto que o trabalho é atividade de um sujeito vivo, enquanto realização de faculdades, possibilidades e capacidades do sujeito trabalhador (Iamamoto, 2007). Isto é, falamos de uma potência em ato. Existe, sim, um trabalho do assistente social e processos de trabalho nos quais se envolve na condição de trabalhador especializado. O trabalho, força de trabalho em ação, é algo temporal, que só pode existir no sujeito vivo. É um movimento criador do sujeito (Idem, p. 429).

Ao assistente social que atua no campo da saúde torna-se importante trazer à tona que talvez a saúde seja uma das políticas sociais que manifestam uma diversidade enorme de demandas e necessidades da vida humana. Não é possível realizar ações estanques e padronizadas em políticas públicas que atuam diretamente sobre a vida. Tomar a análise de Iamamoto (2007) representa repensar as ferramentas de trabalho, seu objeto, mas principalmente repensar o próprio trabalho do assistente social como potência, constituinte - um trabalho que trará à tona manifestações da questão social que se conectam na sua dimensão micro e macropolítica na rotina de atuação desse profissional.

$\mathrm{O}$ que os novos movimentos sociais, e aqui me refiro unicamente ao campo da saúde, trazem como elemento de análise é que uma das atuais manifestações da questão social se insere na apropriação monopolista do produto do trabalho coletivo. A posse de patentes de medicamentos e do direito do exercício da profissão nos remetem a uma apropriação generalizada do trabalho social (general intelect). Isto não significa mera transferência das novas lutas sociais para a dimensão mundializada de apropriação global do capital ou simplesmente mais uma forma de acumulação de capital fetichizado, mas sim uma ampla expropriação do trabalho criado e acumulado coletivamente pela classe trabalhadora. A pauta gestada pelos movimentos sociais tem nos sinalizado que o direito à vida representa também ter direito aos direitos: direito a medicamentos, a atendimentos que contemplem a dimensão humana, a adoecer sem ser desrespeitado nas suas relações de trabalho, a exercer seu trabalho (nas mais

\footnotetext{
Saúde (OMS). As reuniões ocorrem sempre em países diferentes. A presidência pro tempore neste momento é da Argentina. O Mercosul Salud está hoje também relacionado ao Ministério das Relações Exteriores no Brasil. Muitas de suas lutas estão sendo ampliadas no Fórum Social Mundial da Saúde. O movimento, em âmbito de Estado, se reúne em um Subgrupo Trabalho do acordo Mercosul (SGT 11). O site para ter acesso a todas as atas, relatórios e demais documentos produzidos pelo movimento é <www.mercosulsalud.org>.
} 
diversas formas), ter acesso à água potável, saneamento, alimentação e a um meio ambiente sem poluição, por exemplo.

Decifrar as novas mediações por meio por meio das quais se expressa a questão social, hoje, é de fundamental importância para o serviço social em uma dupla perspectiva para que se possa tanto apreender as várias expressões que assumem, na atualidade, as desigualdades sociais — sua produção e reprodução ampliada - quanto projetar e forjar formas de resistência e de defesa da vida. (Iamamoto, 2001, p. 28)

Mesmo o trabalho do assistente social, sob a égide de um capital financeirizado, traz as repercussões disso. A atuação deste profissional não é deslocada das bases sociais que a sustentam. Nesta fase de acumulação fetichizada do capital, o Serviço Social está sendo convidado a pensar os Estados nacionais e suas estratégias de reprodução que atingem profundamente as políticas públicas, entre elas as políticas sociais de saúde, com complexas incidências na vida humana e refrações que nos permitem repensar as políticas públicas. O que dizer da criação de um sistema de seguridade social mundial, como será discutido em 2010 na primeira conferência que será realizada no Brasil? Como pensar uma política de saúde como vem sendo apregoada pelo Mercosul? Uma política de Estados, e não de um Estado.

O SUS, modelo brasileiro que nasceu das lutas sociais, tem servido de parâmetro para esse debate em toda a América Latina. As respostas e as formas de resistência ao capital mundializado também têm sido manifestadas de forma mundializada. Os movimentos sociais atuais têm apontado para isso. Se o neoliberalismo pautou a focalização, a agenda dos movimentos é formada de novas formas de luta que transcendam as fronteiras dos Estados nacionais. E não se trata de mais um discurso de "solidariedade" ou a busca por um prêmio Nobel; refere-se a estar atento às estratégias do capital em se disseminar como ordem única, parasitária, apropriando-se unicamente do trabalho humano em todo o planeta.

Deve se atentar para esse momento histórico como um novo momento e uma outra forma de pautar a agenda pública, visto que esses novos movimentos sociais preencheram as plataformas de governo da atual esquerda que chegou em bloco ao Cone Sul. A primeira década dos anos 2000 foi marcada pelas causas ligadas à terra, à questão indígena, aos negros, aos pobres, trabalhadores desempregados e ao ambiente. Mas também por dimensões novas das lutas so- 
ciais: a luta por produção de conhecimento e por direito à informação, por mais democracia e transparência.

Nessa tendência, identificamos claramente os processos de trabalho dos assistentes sociais como essenciais. A contribuição do Serviço Social a este momento histórico é distante de padrões fordistas de produção na gestão do seu trabalho, mas claramente pautada pela sua primazia: produção de informação qualificada na era da produção do acesso. Proporcionar o ter direito aos direitos e, assim, concretizar a democracia.

Artigo recebido em mar./2010 aprovado em jun./2010

\section{Referências bibliográficas}

BRAVO, M. I. S. Serviço Social e reforma sanitária: lutas sociais e práticas profissionais. São Paulo/Rio de Janeiro: Cortez/Editora UFRJ, 1996.

2001. . et al. Política social e democracia. São Paulo: Cortez; Rio de Janeiro: UERJ,

BRAVO, M. I. S.; MATOS, M. C. A saúde no Brasil: reforma sanitária e ofensiva neoliberal. In: BRAVO, M. I. S. (Org.). Política social e democracia. São Paulo: Cortez; Rio de Janeiro: UERJ, 2001.

COCCO, G. Trabalho e cidadania: produção de direitos na era da globalização. São Paulo: Cortez, 2000.

HARVEY, David. Condição pós-moderna. São Paulo: Edições Loyola, 1989.

LOBATO, L. V. C.; FLEURY, S. Seguridade social, cidadania e saúde. Rio de Janeiro: Cebes, 2009.

IAMAMOTO, M. Serviço Social em tempo de capital fetiche: capital financeiro, trabalho e questão social. São Paulo: Cortez, 2007.

. O Serviço Social na contemporaneidade: trabalho e formação profissional. 4. ed. São Paulo: Cortez, 2001. p. 63.

MOTA, A. E. Cultura da crise e seguridade social: estudo sobre as tendências da previdência e da assistência social brasileira nos anos 80 e 90. São Paulo: Cortez, 1995.

NETTO, J. P. Ditadura e Serviço Social: uma análise do Serviço Social pós-64. 3. ed. São Paulo: Cortez, 1996.

REZENDE, I.; CAVALCANTI, L. F. Serviço Social e políticas sociais. Rio de Janeiro: Editora UFRJ, 2006. 